\title{
Principles of Rehabilitation and Reactivation: Interstitial Lung Disease, Sarcoidosis and Rheumatoid Disease with Respiratory Involvement
}

\author{
Anne E. Holland ${ }^{\mathrm{a}-\mathrm{c}}$ Leona M. Dowman ${ }^{\mathrm{a}} \mathrm{b}, \mathrm{d} \quad$ Catherine J. Hill ${ }^{\mathrm{b}, \mathrm{d}}$ \\ ${ }^{a}$ Department of Physiotherapy, La Trobe University, ${ }^{b}$ Institute for Breathing and Sleep, ${ }^{\mathrm{c}}$ Department of \\ Physiotherapy, Alfred Health, and ${ }^{\mathrm{d}}$ Department of Physiotherapy, Austin Health, Melbourne, Australia
}

\section{Key Words}

Interstitial lung diseases . Connective tissue diseases .

Exercise

\begin{abstract}
The interstitial lung diseases (ILDs) are characterised by dyspnoea on exertion, exercise-induced hypoxaemia, reduced skeletal muscle function and exercise intolerance. Evidence from nine randomised controlled trials shows that pulmonary rehabilitation improves exercise capacity, dyspnoea and quality of life in ILD, with moderately large effect sizes from 0.59 to 0.68 . Participants with idiopathic pulmonary fibrosis, the most common and most progressive of the ILDs, achieve benefits in exercise capacity and quality of life that are of equal magnitude to those seen in other ILDs, with effect sizes from 0.59 to 0.75 . Whole body exercise training is a core component of pulmonary rehabilitation for ILD. The standard exercise prescription used for other chronic lung diseases is effective in ILD, including 8 weeks of training with at least two supervised sessions per week and at least $30 \mathrm{~min}$ of aerobic training per session. However, the unique presentation and underlying pathophysiology of ILD may require modifications of the exercise prescription for individual patients. Those with connective tissue disease may present with joint pain and stiffness that require modification of the standard exercise prescription, including reduction in weight-bearing exercise. Some patients with severe disease
\end{abstract}

may present with distressing dyspnoea that limits the intensity or progression of training. Because exercise-induced hypoxaemia is common in ILD and more severe than seen in other chronic lung diseases, pulmonary rehabilitation should be provided in a setting where supplemental oxygen therapy is available. Pulmonary rehabilitation programs offer the opportunity to address other critical aspects of ILD care, including management of comorbidities, symptoms and mood.

(c) 2015 S. Karger AG, Basel

The interstitial lung diseases (ILDs) are a diverse group of chronic lung conditions characterised by lung inflammation and/or scarring, giving rise to a restrictive ventilatory pattern. In some cases ILD is a feature of an underlying systemic disease process, such as sarcoidosis or connective tissue disease including rheumatoid arthritis. It may also occur due to occupational exposures, such as asbestosis or silicosis. Idiopathic pulmonary fibrosis (IPF), the most common and most lethal form of ILD, has no established cause. Regardless of the underlying cause, people with ILD share a common clinical presentation

Previous article in this series: Osadnik CR, Rodrigues FMM, Camillo CA, Loeckx M, Janssens W, Dooms C, Troosters T: Principles of rehabilitation and reactivation. Respiration 2015;89:2-11.

\section{KARGER 125}

2015 S. Karger AG, Basel

0025-7931/15/0892-0089\$39.50/0

E-Mail karger@karger.com

www.karger.com/res
Anne E. Holland

Department of Physiotherapy, La Trobe University

Level 4, The Alfred Centre, 99 Commercial Rd

Melbourne, VIC 3004 (Australia)

E-Mail a.holland@ alfred.org.au 
which includes distressing dyspnoea, exercise intolerance and persistent cough.

In recent years pulmonary rehabilitation has become an accepted treatment for people with ILD. A survey of pulmonary rehabilitation services across the world reported that $74 \%$ of programs accepted referrals for patients with this diagnosis [1]. This is consistent with international standards for best practice in IPF management $[2,3]$ and pulmonary rehabilitation [4], which promote inclusion of people with ILD in pulmonary rehabilitation programs on the basis of emerging science that suggests clinically important benefits. However, provision of pulmonary rehabilitation in ILD poses some unique challenges due to underlying pathophysiology, exercise responses and symptoms. The aim of this review is to describe the clinical features of ILD that may be amenable to pulmonary rehabilitation, provide practical guidance for exercise training (including relevant safety considerations) and identify other components of pulmonary rehabilitation that may be beneficial for people with ILD.

\section{The Problem}

In IPF, progressive lung fibrosis is thought to be related to recurrent injury to the alveolar epithelium followed by aberrant wound healing [5]. Clinically, this manifests as a reduction in both forced vital capacity and diffusing capacity of the lung for carbon monoxide (DLCO). A similar pattern of respiratory function impairment is seen in other fibrosing interstitial pneumonias (e.g. non-specific interstitial pneumonia, cryptogenic organising pneumonia), although typically disease progression is slower and there is a more favourable prognosis. ILD may occur in any of the connective tissue diseases (CTD-ILD), also referred to as collagen vascular diseases, including systemic sclerosis (SSc), rheumatoid arthritis and polymyositis/dermatomyositis [6]. The CTD-ILDs are characterised by other systemic manifestations including arthropathy, myopathy and vasculopathy. Granulomatous ILD is the most common manifestation of sarcoidosis [7]. Pulmonary hypertension may accompany ILD, either in severe disease (e.g. severe IPF) or as a manifestation of an underlying disease process (e.g. SSc), and it affords a poor prognosis $[8,9]$.

Exercise limitation is a common feature of ILD. There is a strong relationship between reduced exercise capacity and increased mortality, particularly in IPF [10]. Exercise capacity is frequently a stronger predictor of prog- nosis than resting respiratory function $[11,12]$. There are multiple contributors to exercise limitation in ILD, with gas exchange limitation and circulatory limitation playing important roles. Reduction in diffusing capacity, due to thickening of the alveolar-capillary membrane or destruction of the pulmonary capillary bed, becomes critical during exertion and results in oxygen diffusion limitation and ventilation-perfusion mismatch [13]. Marked oxyhaemoglobin desaturation during exercise is often present $[14,15]$. Those patients with more severe diffusion limitation at rest exhibit greater oxyhaemoglobin desaturation during exercise and a lower exercise capacity [16]. Typically patients with IPF show a larger increase in $\mathrm{P}(\mathrm{A}-\mathrm{a}) \mathrm{O}_{2}$ during exercise than those with sarcoidosis [17] or asbestosis [18], probably due to a greater degree of interstitial fibrosis in IPF. Circulatory impairment, resulting from pulmonary capillary destruction and hypoxic pulmonary vasoconstriction, may also be a significant limitation to exercise capacity [19]. In IPF there is a strong relationship between elevation in pulmonary artery pressures and reduction in exercise performance $[20,21]$. Abnormal heart rate responses to exercise have been documented in advanced ILD, including reduced chronotropic response and slower heart rate recovery $[22,23]$. Reduced heart rate response to exercise is associated with both poor exercise capacity and poor prognosis [23]. Cardiac dysfunction during exercise has been documented in patients with sarcoidosis, which may represent granulomatous infiltration of the myocardium [24].

The non-cardiorespiratory manifestations of ILD also contribute to exercise intolerance. Quadriceps force is reduced in the fibrotic idiopathic interstitial pneumonias (IPF and non-specific interstitial pneumonia) [25], sarcoidosis [26,27] and rheumatoid arthritis [28], with average values that are $20-35 \%$ lower than healthy controls. Lower quadriceps force is consistently associated with reduced peak exercise capacity $[26,29]$ and reduced functional exercise capacity [25-27, 30,31], regardless of the underlying type of ILD. In some ILDs, peripheral muscle function appears to worsen as the disease progresses [27, 32]. Importantly, lower peripheral muscle strength is also associated with worse patient-reported outcomes such as greater activity limitation [32], lower quality of life [26, 27] and higher levels of fatigue [26, 27].

The causes of skeletal muscle dysfunction in ILD are not well documented. It is likely that deconditioning related to physical inactivity plays a role similar to that seen in other chronic lung conditions, particularly in advanced ILD [33], but this has not been extensively studied. Factors specific to the underlying ILD diagnosis may contrib- 
ute to skeletal muscle weakness. In rheumatoid arthritis, reduced quadriceps force has been associated with longer disease duration, a greater number of joints affected and current use of corticosteroids [34]. The impact of corticosteroids in sarcoidosis is less clear, with conflicting findings regarding its impact on quadriceps force $[26,27]$. These contrasting findings may be related to the underlying cause of myopathy; muscle sarcoidosis is rare, but typically responds well to systematic corticosteroid treatment [35], whereas steroid-induced myopathy may occur in other patients using corticosteroids to treat other disease manifestations. In SSc, skeletal muscle dysfunction is worse in those with longer disease duration, and in those with diffuse cutaneous SSc compared to limited cutaneous SSc [36]. There is also evidence of skeletal muscle vasculopathy in SSc, which may impair peripheral muscle function even in the absence of weakness [37]. These complex and disease-specific factors emphasise the importance of considering skeletal muscle function when evaluating exercise intolerance in ILD.

People with ILD typically present with a range of comorbidities which may also contribute to exercise intolerance, poor functional status and reduced quality of life. Coronary artery disease is more prevalent in pulmonary fibrosis than in community dwelling controls, even after allowing for smoking status, and may occur in up to one third of patients [38]. Those patients with IPF and coronary artery disease have significantly worse survival than those with IPF alone [39]. Concurrent pulmonary fibrosis and emphysema may occur in up to $10 \%$ of patients, occurring predominantly in males with a history of cigarette smoking. These individuals have increased prevalence of pulmonary hypertension compared to those without emphysema, and have increased requirements for supplemental oxygen [40]. Anxiety is present in up to one third of individuals with ILD, especially in those with higher levels of dyspnoea [41]. Depression is also common, occurring in approximately $25 \%$ of patients with ILD, occurring more often in those with higher levels of dyspnoea and a greater number of comorbidities [41]. Depression does not resolve in the absence of treatment [42]. The degree of impairment in lung function is not a predictor of either anxiety or depression, which occurs across the spectrum of disease severity [41].

In summary, people with ILD experience marked exercise intolerance and a large symptom burden. Whilst the underlying pathophysiology of lung disease is a significant contributor, other factors such as skeletal muscle dysfunction and comorbidity may also impact on exercise capacity, functional performance and well-being. These

ILD, Sarcoidosis and Rheumatoid Disease with Respiratory Involvement factors may be amenable to exercise-based rehabilitation programs. Provision of effective rehabilitation for ILD is more critical than ever before. New pharmacological treatments are emerging that allow patients to achieve disease stability, particularly in IPF $[43,44]$; this will increase the importance of supportive treatments such as rehabilitation that allow patients to 'live well' with a chronic disease and will widen the window in which effective rehabilitation can be provided. The evidence for rehabilitation in ILD is presented in the following section.

\section{Exercise Training}

\section{Evidence for Efficacy of Exercise Training}

Whole body exercise training is a core component of pulmonary rehabilitation for people with ILD. Evidence from randomised controlled trials (RCTs) suggests that it confers clinically meaningful benefits. A recent Cochrane review has synthesised the results of nine RCTs of pulmonary rehabilitation for ILD, all of which included exercise training [45]. Compared to usual care, pulmonary rehabilitation improved the 6-min walk distance (6MWD) by $44 \mathrm{~m}$ (95\% CI: 26-47). This is similar to the gains in functional exercise capacity seen following pulmonary rehabilitation in people with chronic obstructive pulmonary disease (COPD) [46], where it is a more established treatment. The increase in 6MWD following training exceeds the minimal important difference [47], suggesting that this improvement is meaningful to patients. Improvements in peak exercise capacity, dyspnoea and quality of life are also evident following pulmonary rehabilitation with moderately large effect sizes (fig. 1). Pulmonary rehabilitation may impact on other important symptoms in ILD, with non-randomised studies reporting significant improvements in depression [48-50] and fatigue [51], with a trend towards reduced anxiety [51]. Whilst there is no evidence that pulmonary rehabilitation can modify the course or prognosis of any of the ILDs, current data suggest that it has an important impact on patient centred outcomes and should be considered as standard therapy in people with symptomatic disease.

The body of evidence supporting pulmonary rehabilitation is growing rapidly, but there are limitations to our knowledge. There is little information regarding the mechanism by which pulmonary rehabilitation improves outcomes for people with ILD. It is likely that exercise training improves skeletal muscle function, similar to its effects in COPD [52], but this hypothesis has not been examined in robust trials. A non-randomised study 
Fig. 1. Efficacy of exercise training in ILD on clinical outcomes in randomised controlled trials. Data are effect sizes and their 95\% CI calculated from Dowman et al. [45] and Gaunaurd et al. [54]. HRQOL = Health-related quality of life.

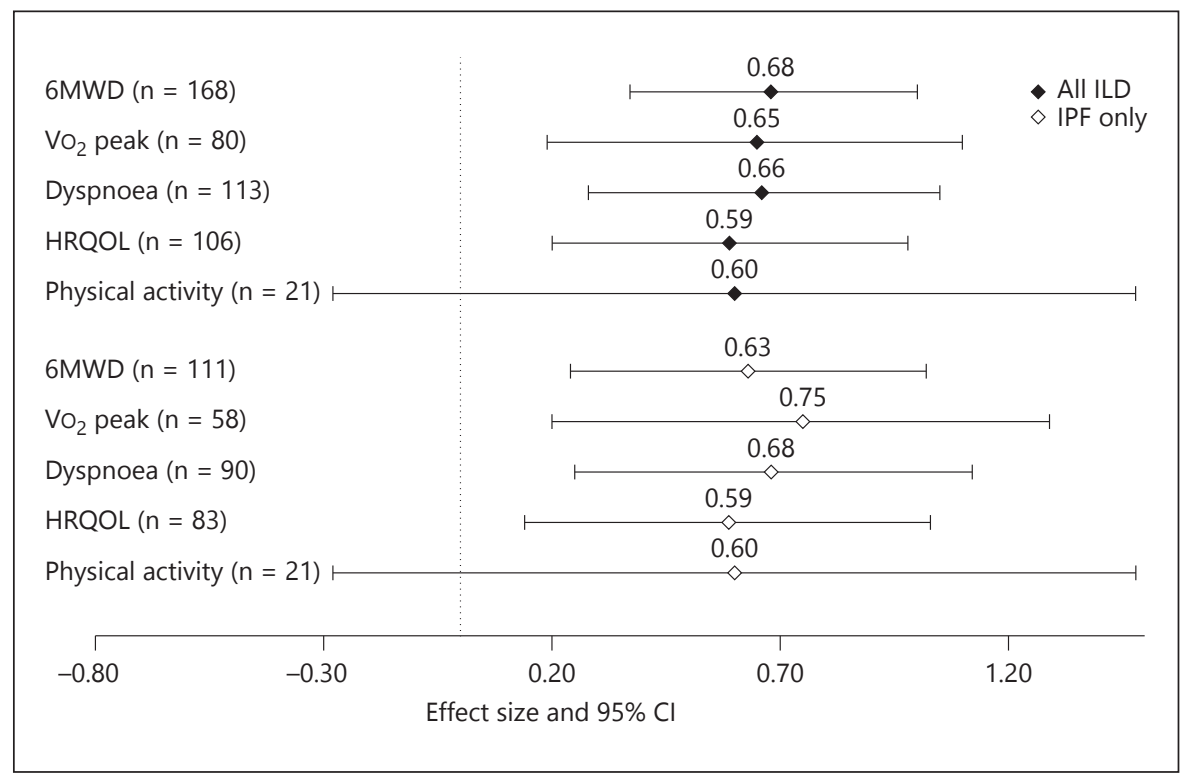

showed significant improvement in quadriceps force after a 12-week exercise-based rehabilitation program in people with restrictive lung disease [53], suggesting that this may be a fruitful area for further investigation. An important aim of pulmonary rehabilitation is to improve physical activity in daily life [4]. In ILD the impact of pulmonary rehabilitation on physical activity has not yet been defined, with only one trial examining this outcome to date [54] and no statistically significant findings, probably due to the small number of included subjects (fig. 1). Finally, the longer-term benefits of exercise training for ILD remain to be established. One study examined outcomes at 6 months following training, at which point the positive effects on exercise capacity and quality of life were no longer evident, probably due to disease progression in patients with IPF [55]. This contrasts with findings from an uncontrolled trial where improvements in $6 \mathrm{MWD}$ and quality of life were maintained at 6 months, although the high dropout rate $(28 \%)$ may have influenced this finding [50]. Further work is required to define the longer-term impacts of exercise training, particularly in the context of recent advances in pharmacological management of IPF, and to ensure that the benefits can be sustained over time.

Despite some gaps in our knowledge, consistent evidence of benefit from RCTs provides a rationale for including pulmonary rehabilitation as part of usual care for ILD. Current IPF treatment guidelines contain a weak recommendation for pulmonary rehabilitation [2]. This weak recommendation indicates that pulmonary rehabil- itation should be used in the majority of people with IPF, whilst recognizing that some patients may choose not to undertake this treatment, and that there is uncertainty surrounding its longer-term effects [2]. More recently, a guideline from the United Kingdom concluded that pulmonary rehabilitation was highly likely to be cost-effective as a means to improve quality of life for people with IPF and should be offered at 6- to 12-month intervals [3]. Similar treatment recommendations are yet to be made for other ILDs, but the current evidence base suggests that routine referral to pulmonary rehabilitation is likely to be beneficial.

\section{Patient Selection for Exercise Training Programs}

The inclusion criteria for most RCTs of exercise training in ILD have been broad and participants have had a wide range of diagnoses (fig. 2). Forty percent of trial participants had a diagnosis of IPF (fig. 2), which is the most prevalent of the ILDs. Some people with IPF experience rapid disease progression associated with distressing symptoms and early death, and this has previously raised concerns that pulmonary rehabilitation may not be worthwhile in this group. More recently, however, it has become clear that the clinical course of IPF is variable, with most individuals experiencing more gradual disease progression and some experiencing long periods of stability [2]. This suggests that a universally pessimistic outlook is not warranted and that there is often opportunity for effective rehabilitation. A subgroup analysis for IPF participants taking part in RCTs of pulmonary rehabilita- 


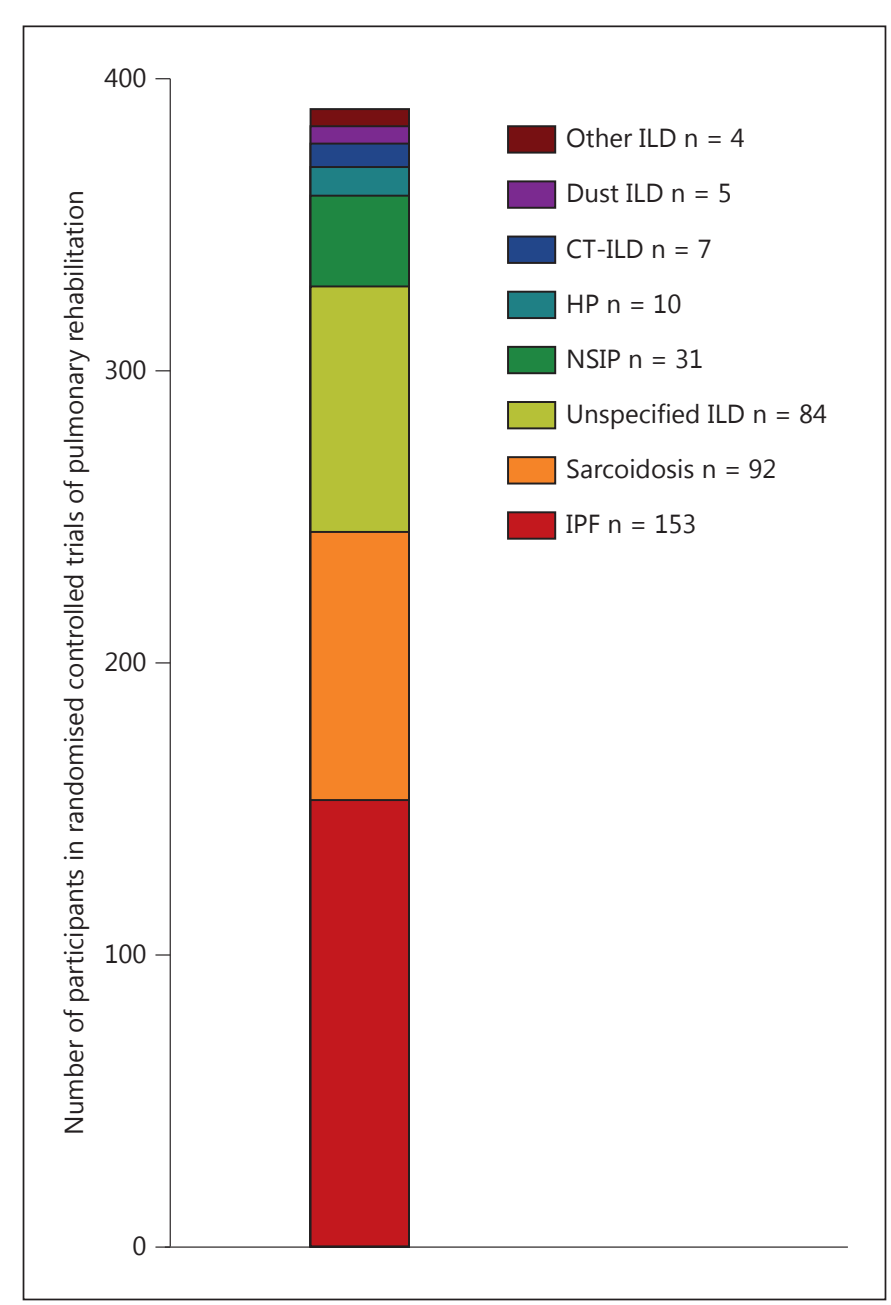

Fig. 2. Diagnoses of people with ILD included in RCTs of pulmonary rehabilitation. NSIP $=$ Non-specific interstitial pneumonia; $\mathrm{HP}=$ hypersensitivity pneumonitis; CT-ILD = connective tissuerelated ILD.

tion shows effects on clinical outcomes that are of equal magnitude to those in the ILD group as a whole (fig. 1b). A Cochrane review showed that the mean improvement in 6MWD following exercise training for IPF was $36 \mathrm{~m}$ (95\% CI: 16-55) [45], which exceeds the minimal important difference for this outcome [47]. These data provide reassurance that pulmonary rehabilitation is clinically useful in IPF.

Whilst it is difficult to draw firm conclusions from existing trials regarding the impact of exercise training in people with non-IPF ILDs, due to smaller numbers of participants or inadequate reporting, there is currently no evidence to suggest adverse effects of exercise training in these groups or that the impact of pulmonary rehabilitation differs according to underlying diagnosis. As a result, all patients with ILD should be provided with the opportunity to enter a pulmonary rehabilitation program if clinically indicated.

The impact of disease severity on the response to exercise training in ILD is unclear. Larger improvements in exercise capacity following pulmonary rehabilitation have been seen in those with a higher FVC, less exerciseinduced desaturation and a smaller degree of disability at baseline $[56,57]$. Those with less desaturation on the baseline 6-min walk test were more likely to experience sustained improvements in exercise tolerance at 6 months following the program [56]. These results suggest that exercise training could be more effective when offered earlier in the disease course. In contrast, other authors have found that a lower 6MWD prior to rehabilitation predicted a larger improvement in 6MWD [50]. Similarly, those with higher levels of baseline dyspnoea achieved greater long-term relief of symptoms [56]. In clinical practice, these data indicate that patients with very low functional exercise capacity and severe symptoms should be offered the opportunity to undertake a pulmonary rehabilitation program and may experience clinically important benefits. However, early referral to rehabilitation should be considered for all patients, especially in patients with IPF, as less severe physiological limitation may provide greater opportunity to successfully undertake training.

\section{Characteristics of Exercise Training Programs for ILD}

Eight out of the nine RCTs of exercise training in ILD (89\%) have been conducted in the outpatient setting [55, 58-64]. Characteristics of the training programs are shown in table 1 . The exercise training protocols used in ILD are consistent with those recommended for use in pulmonary rehabilitation programs for people with COPD [65]. Most programs are between 8 and 12 weeks in length, include a minimum of two supervised exercise sessions each week and at least $30 \mathrm{~min}$ of aerobic training in each session, with progression of the training load over the course of the program (table 1). Both continuous and interval aerobic training protocols have been used, along with a variety of methods for resistance training. Overall, these training strategies have been effective in delivering the expected outcomes of pulmonary rehabilitation, including improved exercise capacity and better quality of life [45]. However, it must be acknowledged that the optimal exercise training strategy for people with ILD is not known and to date no studies have tested the merits of one exercise prescription versus another. It is likely that the well-established principles of exercise training for people 
Table 1. Characteristics of outpatient exercise training programs from RCTs in people with ILD

\begin{tabular}{lll}
\hline & Median & Range \\
\hline Length of program, weeks & 10 & $5-12$ \\
Number of supervised sessions/week & 2 & $2-5$ \\
Duration of aerobic training, min & 30 & $30-40$ \\
\hline & & Number of studies (\%) \\
\hline Mode of training & aerobic only & $3(38)$ \\
Starting intensity for aerobic training & aerobic and resistance & $4(50)$ \\
& $60-80 \%$ of maximum HR & $1(13)$ \\
Continuous or interval training & $60 \%$ peak power on cycle ergometer & $2(25)$ \\
& $80 \%$ of walking speed on 6MWT & $2(25)$ \\
Nature of resistance training & continuous & $2(25)$ \\
& interval & $1(13)$ \\
Components of program & both & $1(13)$ \\
& free weights & $1(13)$ \\
Other interventions included & elastic bands & $2(25)$ \\
& body weight/functional exercises & $1(13)$ \\
& exercise alone & $4(50)$ \\
& exercise and other interventions & $5(63)$ \\
& education & $4(50)$ \\
& nutritional advice & $2(25)$ \\
& stress management & $1(13)$ \\
& physiotherapy & $1(13)$ \\
& psychosocial support & $1(13)$ \\
\hline
\end{tabular}

Data are from randomised controlled trials of pulmonary rehabilitation in ILD reported in a Cochrane review [45]. Not all outcomes are reported in all studies. HR = Heart rate.

with chronic lung disease, documented in many international standards $[4,65]$, are applicable to most individuals across the range of ILDs. There are, however, some special considerations for exercise training in this population which will be discussed in the following section.

\section{Safety and Special Considerations}

Exercise-induced hypoxemia is common in ILD and has been documented during exercise testing and exercise training, as well as during activities of daily life. In a large cohort of patients $(n=741)$ undertaking the 6 -min walk test prior to rehabilitation, the average reduction in oxyhaemoglobin saturation $\left(\mathrm{SpO}_{2}\right)$ in patients with ILD was larger than that seen in COPD (5.7 vs. 7.3\%), and the nadir $\mathrm{SpO}_{2}$ was also lower (mean 87 vs. 89\%) [66]. The test was stopped due to excessive desaturation $\left(\mathrm{SpO}_{2}<80 \%\right)$ in $10 \%$ of individuals with ILD, compared to $5 \%$ of individuals with COPD. Consistent with these observations, 24-hour monitoring of $\mathrm{SpO}_{2}$ in a group of 19 individuals with ILD who were not hypoxaemic at rest revealed that all patients desaturated during waking hours [67]. Time spent with $\mathrm{SpO}_{2}<88 \%$ varied between 0.3 and $47 \%$ of waking hours, with greater desaturation in those with more severe disease and in those who were more physically active. This study also found that patients with ILD had frequent cardiac arrhythmias, both during both daily life and the 6-min walk test, which were mostly atrial premature contractions or ventricular premature contractions [67]. These arrhythmias did not consistently occur during periods of desaturation, were asymptomatic and did not require treatment. Pulmonary hypertension is common in patients with ILD at rest and may also be induced by exercise. In a group of 8 patients with ILD and mean DLCO 44\% predicted, the average systolic pulmonary artery pressure on echocardiography rose from $28 \mathrm{~mm} \mathrm{Hg}$ (SD 6) at rest to $73 \mathrm{~mm} \mathrm{Hg}$ (SD 14) at peak exercise [68].

Despite these marked physiological abnormalities, exercise testing and training for ILD has an excellent safety profile. No adverse events have been reported during 
6-min walk testing for ILD; however, it should be acknowledged that this is based primarily on one large study where the test was stopped if desaturation to less than $80 \%$ occurred [66]. A recent Cochrane review found no reports of adverse events during exercise training for ILD [45]. In all trials, monitoring during training consisted of pulse oximetry, which is consistent with published standards for pulmonary rehabilitation programs $[4,65]$. In patients with SSc, a forehead probe may provide more accurate oximetry measures than a finger probe, due to $\mathrm{cu}-$ taneous involvement [69]. Supplemental oxygen has been used during many exercise training studies to maintain $\mathrm{SpO}_{2}$ at acceptable levels, which was defined as above $85 \%$ [55], above $88 \%$ [59] or above $90 \%$ [58]. Supplemental oxygen may result in better oxygen delivery to the tissue, but it does not appear to impact on exercise-induced elevation in pulmonary artery pressures [68].

Supplemental oxygen during exercise training may have a role in optimising the outcomes of rehabilitation for people with ILD. Those patients who experience marked desaturation during exercise may have difficulty achieving the required exercise training intensity, either due to intolerable symptoms or because local safety guidelines require that exercise intensity is reduced in order to maintain an acceptable $\mathrm{SpO}_{2}$. In such cases the provision of supplemental oxygen, administered according to relevant institutional protocols, may be useful to assist patients in achieving an effective training intensity which can be progressed over time. More rapid progression of training intensity with supplemental oxygen has been demonstrated in people with COPD who received supplemental oxygen during exercise training compared to those who received intra-nasal air, with greater gains in exercise capacity at the end of rehabilitation [70]. However, to date no studies have evaluated the impact of supplemental oxygen on training outcomes in ILD. Current guidelines for pulmonary rehabilitation suggest that supplemental oxygen should be provided during training for those who would fulfil the criteria for use of ambulatory oxygen therapy [65]. Given the prevalence of exerciseinduced hypoxaemia in ILD [66], many patients will meet this criterion. As a result, it is important that people with ILD undergo rehabilitation in a centre with the capacity to provide supplemental oxygen during training.

Exercise-induced dyspnoea may be severe, distressing and even intolerable for some people with ILD. This may compromise the effectiveness of exercise training programs [57]. This issue is particularly important for patients who are preparing for lung transplantation, in whom it is important to maintain optimal physical func-

ILD, Sarcoidosis and Rheumatoid Disease with Respiratory Involvement tion despite the limitations of severe disease. A number of strategies have been proposed to optimise training intensity and increase the training stimulus to peripheral muscle, whilst minimising symptoms [71]. These strategies include interval training, partitioning of the exercising muscle mass and neuromuscular electrical stimulation (NMES).

Interval training consists of periods of high-intensity exercise interspersed with recovery periods. In people with COPD, interval training and continuous training produce equivalent outcomes for exercise capacity, quality of life and skeletal muscle adaptations, as long as the same total work is performed [72]. Interval training resulted in lower dyspnoea scores in some $[73,74]$ but not all $[75,76]$ studies.

Partitioning of the exercising muscle mass, achieved by reducing the volume of exercising muscle, reduces the ventilatory load associated with exercise. This may be useful for patients who cannot tolerate high-intensity exercise due to dyspnoea. In COPD, it has been demonstrated that compared to cycling with two legs, cycling with only one leg at the same relative intensity increased constant power exercise time almost fourfold [77]. Randomised trials have shown that one-legged cycling training leads to greater improvements in peak power and peak $\mathrm{VO}_{2}$ compared to conventional cycle training with two legs $[78,79]$.

NMES involves applying an intermittent electrical current to a superficial peripheral muscle, most commonly the quadriceps femoris, in order to provide a training stimulus to muscle with minimal ventilatory demands. In patients with COPD and severe functional impairment, addition of NMES to an exercise training program resulted in better peripheral muscle function and reduced dyspnoea $[80,81]$. Because NMES provokes minimal respiratory symptoms during training, it may be a useful strategy for the most severely debilitated or symptomatic patients, either alone or combined with whole body exercise.

Data regarding the efficacy of all these strategies must currently be extrapolated from studies in people with COPD. More research is needed in order to determine the optimal exercise training prescription for people with ILD, particularly in those with severe disease and those awaiting lung transplantation.

Because ILD is often only one manifestation of a systemic condition, patients may present with other physical limitations which require modifications to the exercise training program. Arthropathy is common in patients with connective tissue disorders, with joint pain and lim- 
itation to range of movement. Exercise training programs that minimise weight-bearing through the lower limbs may be better tolerated in those with significant lower limb joint pathology (e.g. cycling rather than walking training). In COPD, water-based training is an effective alternative to land-based training for patients with comorbidities [82], although it has not yet been tested in ILD. Care should be taken that upper-limb exercise programs do not exacerbate shoulder pain in those with upper-limb arthropathy.

\section{Other Components of Pulmonary Rehabilitation for ILD}

Education and disease management training are considered integral components of a comprehensive pulmonary rehabilitation program. Disease education and support have been identified as unmet needs by people with IPF [83], and pulmonary rehabilitation provides an ideal opportunity to provide these. However, the specific content of the non-exercise components of pulmonary rehabilitation for people with ILD has not been defined. Dyspnoea and cough are burdensome symptoms in ILD that adversely impact on quality of life [84]. Patients may benefit from sharing their experiences in managing these difficult symptoms. Given the prevalence of anxiety and depression in ILD [41], advice on effective strategies to manage mood may also be appropriate and the contribution of a psychologist is desirable. Information about supplemental oxygen and lung transplantation may be appropriate for some patients. Pulmonary rehabilitation may also provide opportunity to provide information on advance care planning; patients with ILD report positive experiences from such discussions in the context of group education during pulmonary rehabilitation [85]. It must be recognised that much of the content of existing education programs in pulmonary rehabilitation was designed for people with COPD and may not be appropriate for most patients with ILD. This includes information about treatments specifically designed for people with obstructive lung disease, such as pursed lip breathing, inhaler techniques and COPD action plans. However, some key elements of disease management are consistent across chronic lung diseases and the existing curriculum will be appropriate, such as the importance of regular exercise and maintaining a healthy weight.

\section{Conclusion}

Pulmonary rehabilitation is an important element of the comprehensive care of people with ILD. Evidence from RCTs shows that pulmonary rehabilitation programs which include exercise training result in clinically important improvements in exercise capacity, symptoms and quality of life. Exercise prescription protocols documented in international standards for pulmonary rehabilitation in COPD are effective in ILD. Exercise-induced desaturation is very common and exercise training should take place in settings where supplemental oxygen is available. Whilst a variety of strategies exist to optimise training outcomes in those who are severely limited by dyspnoea, including interval training, partitioning and NMES, to date these have not been tested in ILD. Arthropathy related to the underlying cause of ILD may require modification of training programs, including minimisation of weight-bearing exercise in those with lower limb pain. Pulmonary rehabilitation programs are an ideal opportunity to provide disease-specific education and support for people with ILD, including strategies to manage symptoms and mood.

\section{Financial Disclosure and Conflicts of Interest}

The authors have no conflict of interest to declare.

\section{References}

1 Spruit MA, Pitta F, Garvey C, Zu Wallack RL, Roberts CM, Collins EG, Goldstein R, McNamara R, Surpas P, Atsuyoshi K, LopezCampos JL, Vogiatzis I, Williams JE, Lareau S, Brooks D, Troosters T, Singh SJ, Hartl S, Clini EM, Wouters EF: Differences in content and organisational aspects of pulmonary rehabilitation programmes. Eur Respir J 2014; 43:1326-1337.

\footnotetext{
Raghu G, Collard HR, Egan JJ, Martinez FJ, Behr J, Brown KK, Colby TV, Cordier JF, Flaherty KR, Lasky JA, Lynch DA, Ryu $\mathrm{JH}$, Swigris JJ, Wells AU, Ancochea J, Bouros D, Carvalho C, Costabel U, Ebina M, Hansell DM, Johkoh T, Kim DS, King TE Jr, Kondoh Y, Myers J, Muller NL, Nicholson AG, Richeldi L, Selman M, Dudden RF, Griss BS, Protzko SL, Schunemann HJ:
}

An official ATS/ERS/JRS/ALAT statement: idiopathic pulmonary fibrosis: evidencebased guidelines for diagnosis and management. Am J Respir Crit Care Med 2011;183: 788-824.

3 The Diagnosis and Management of Suspected Idiopathic Pulmonary Fibrosis: NICE Clinical Guideline 163. London, National Institute for Health and Care Excellence, 2013. 
-4 Spruit MA, Singh SJ, Garvey C, ZuWallack R, Nici L, Rochester C, Hill K, Holland AE, Lareau SC, Man WD, Pitta F, Sewell L, Raskin J, Bourbeau J, Crouch R, Franssen FM, Casaburi R, Vercoulen JH, Vogiatzis I, Gosselink R, Clini EM, Effing TW, Maltais F, van der Palen J, Troosters T, Janssen DJ, Collins E, Garcia-Aymerich J, Brooks D, Fahy BF, Puhan MA, Hoogendoorn M, Garrod R, Schols AM, Carlin B, Benzo R, Meek P, Morgan M, Rutten-van Molken MP, Ries AL, Make B, Goldstein RS, Dowson CA, Brozek JL, Donner CF, Wouters EF: An official American Thoracic Society/European Respiratory Society statement: key concepts and advances in pulmonary rehabilitation. Am J Respir Crit Care Med 2013;188:e13e64.

5 Poletti V, Ravaglia C, Buccioli M, Tantalocco P, Piciucchi S, Dubini A, Carloni A, Chilosi $\mathrm{M}$, Tomassetti S: Idiopathic pulmonary fibrosis: diagnosis and prognostic evaluation. Respiration 2013;86:5-12.

6 6 Fischer A, du Bois R: Interstitial lung disease in connective tissue disorders. Lancet 2012; 380:689-698.

7 Patterson KC, Strek ME: Pulmonary fibrosis in sarcoidosis. Clinical features and outcomes. Ann Am Thorac Soc 2013;10:362370.

8 Lettieri CJ, Nathan SD, Barnett SD, Ahmad S, Shorr AF: Prevalence and outcomes of pulmonary arterial hypertension in advanced idiopathic pulmonary fibrosis. Chest 2006;129: 746-752.

-9 Nihtyanova SI, Schreiber BE, Ong VH, Rosenberg D, Moinzadeh P, Coghlan JG, Wells AU, Denton CP: Prediction of pulmonary complications and long-term survival in systemic sclerosis. Arthritis Rheumatol 2014; 66:1625-1635.

10 Holland AE: Exercise limitation in interstitial lung disease - mechanisms, significance and therapeutic options. Chron Respir Dis 2010;7: 101-111.

-11 Eaton T, Young P, Milne D, Wells AU: Sixminute walk, maximal exercise tests: reproducibility in fibrotic interstitial pneumonia. Am J Respir Crit Care Med 2005;171:11501157.

12 Flaherty KR, Andrei AC, Murray S, Fraley C, Colby TV, Travis WD, Lama V, Kazerooni EA, Gross BH, Toews GB, Martinez FJ: Idiopathic pulmonary fibrosis: prognostic value of changes in physiology and six-minute-walk test. Am J Respir Crit Care Med 2006;174: 803-809.

13 Agusti AG, Roca J, Gea J, Wagner PD, Xaubet A, Rodriguez-Roisin R: Mechanisms of gasexchange impairment in idiopathic pulmonary fibrosis. Am Rev Respir Dis 1991;143: 219-225.

14 Miki K, Maekura R, Hiraga T, Okuda Y, Okamoto T, Hirotani A, Ogura T: Impairments and prognostic factors for survival in patients with idiopathic pulmonary fibrosis. Respir Med 2003;97:482-490.
15 Lama VN, Flaherty KR, Toews GB, Colby TV, Travis WD, Long Q, Murray S, Kazerooni EA, Gross BH, Lynch JP 3rd, Martinez FJ: Prognostic value of desaturation during a 6-minute walk test in idiopathic interstitial pneumonia. Am J Respir Crit Care Med 2003;168: 1084-1090.

16 Holland AE, Dowman L, Fiore J Jr, Brazzale D, Hill CJ, McDonald CF: Cardiorespiratory responses to 6-minute walk test in interstitial lung disease: not always a submaximal test. BMC Pulm Med 2014;14:136.

17 Risk C, Epler GR, Gaensler EA: Exercise alveolar-arterial oxygen pressure difference in interstitial lung disease. Chest 1984;85:6974.

18 Agusti AG, Roca J, Rodriguez-Roisin R, Xaubet A, Agusti-Vidal A: Different patterns of gas exchange response to exercise in asbestosis and idiopathic pulmonary fibrosis. Eur Respir J 1988;1:510-516.

-19 Sudduth CD, Strange C, Cook WR, Miller KS, Baumann M, Collop NA, Silver RM: Failure of the circulatory system limits exercise performance in patients with systemic sclerosis. Am J Med 1993;95:413-418.

20 Glaser S, Noga O, Koch B, Opitz CF, Schmidt B, Temmesfeld B, Dorr M, Ewert R, Schaper C: Impact of pulmonary hypertension on gas exchange and exercise capacity in patients with pulmonary fibrosis. Respir Med 2009; 103:317-324.

-21 Leuchte HH, Baumgartner RA, Nounou ME, Vogeser M, Neurohr C, Trautnitz M, Behr J: Brain natriuretic peptide is a prognostic parameter in chronic lung disease. Am J Respir Crit Care Med 2006;173:744-750.

-22 Swigris JJ, Swick J, Wamboldt FS, Sprunger D, du Bois R, Fischer A, Cosgrove GP, Frankel SK, Fernandez-Perez ER, Kervitsky D, Brown KK: Heart rate recovery after 6-min walk test predicts survival in patients with idiopathic pulmonary fibrosis. Chest 2009;136 841-848.

23 Holland AE, Hill CJ, Glaspole I, Goh N, Dowman L, McDonald CF: Impaired chronotropic response to 6-min walk test and reduced survival in interstitial lung disease. Respir Med 2013;107:1066-1072.

-24 Gibbons WJ, Levy RD, Nava S, Malcolm I, Marin JM, Tardif C, Magder S, Lisbona R, Cosio MG: Subclinical cardiac dysfunction in sarcoidosis. Chest 1991;100:44-50.

25 Mendoza L, Gogali A, Shrikrishna D, Cavada G, Kemp SV, Natanek SA, Jackson AS, Polkey MI, Wells AU, Hopkinson NS: Quadriceps strength and endurance in fibrotic idiopathic interstitial pneumonia. Respirology 2014;19: 138-143.

26 Spruit MA, Thomeer MJ, Gosselink R, Troosters T, Kasran A, Debrock AJ, Demedts MG, Decramer M: Skeletal muscle weakness in patients with sarcoidosis and its relationship with exercise intolerance and reduced health status. Thorax 2005;60:32-38.

27 Marcellis RG, Lenssen AF, Elfferich MD, De Vries J, Kassim S, Foerster K, Drent M: Exer- cise capacity, muscle strength and fatigue in sarcoidosis. Eur Respir J 2011;38:628-634.

28 Madsen OR, Egsmose C, Hansen B, Sorensen $\mathrm{OH}$ : Soft tissue composition, quadriceps strength, bone quality and bone mass in rheumatoid arthritis. Clin Exp Rheumatol 1998; $16: 27-32$

29 Nishiyama O, Taniguchi H, Kondoh Y, Kimura T, Ogawa T, Watanabe F, Arizono S: Quadriceps weakness is related to exercise capacity in idiopathic pulmonary fibrosis. Chest 2005; 127:2028-2033.

30 Watanabe F, Taniguchi H, Sakamoto K, Kondoh Y, Kimura T, Kataoka K, Ogawa T, Arizono S, Nishiyama O, Hasegawa Y: Quadriceps weakness contributes to exercise capacity in nonspecific interstitial pneumonia. Respir Med 2013;107:622-628.

-31 Mengshoel AM, Jokstad K, Bjerkhoel F: Associations between walking time, quadriceps muscle strength and cardiovascular capacity in patients with rheumatoid arthritis and ankylosing spondylitis. Clin Rheumatol 2004; 23:299-305.

32 Kozu R, Jenkins S, Senjyu H: Evaluation of activity limitation in patients with idiopathic pulmonary fibrosis grouped according to medical research council dyspnea grade. Arch Phys Med Rehab 2014;95:950-955.

33 Wallaert B, Monge E, Le Rouzic O, WemeauStervinou L, Salleron J, Grosbois JM: Physical activity in daily life of patients with fibrotic idiopathic interstitial pneumonia. Chest 2013;144:1652-1658.

-34 Kramer HR, Fontaine KR, Bathon JM, Giles JT: Muscle density in rheumatoid arthritis: associations with disease features and functional outcomes. Arthritis Rheum 2012;64:24382450.

35 Nessrine A, Zahra AF, Taoufik H: Musculoskeletal involvement in sarcoidosis. J Bras Pneumol 2014;40:175-182.

36 Marighela TF, Genaro Pde S, Pinheiro MM, Szejnfeld VL, Kayser C: Risk factors for body composition abnormalities in systemic sclerosis. Clin Rheumatol 2013;32:1037-1044.

37 Partovi S, Schulte AC, Aschwanden M, Staub D, Benz D, Imfeld S, Jacobi B, Broz P, Jager KA, Takes M, Huegli RW, Bilecen D, Walker UA: Impaired skeletal muscle microcirculation in systemic sclerosis. Arthritis Res Ther 2012;14:R209.

38 King C, Nathan SD: Identification and treatment of comorbidities in idiopathic pulmonary fibrosis and other fibrotic lung diseases. Curr Opin Pulm Med 2013;19:466-473.

39 Nathan SD, Basavaraj A, Reichner C, Shlobin OA, Ahmad S, Kiernan J, Burton N, Barnett SD: Prevalence and impact of coronary artery disease in idiopathic pulmonary fibrosis. Respir Med 2010;104:1035-1041.

40 Ryerson CJ, Hartman T, Elicker BM, Ley B, Lee JS, Abbritti M, Jones KD, King TE Jr, Ryu J, Collard HR: Clinical features and outcomes in combined pulmonary fibrosis and emphysema in idiopathic pulmonary fibrosis. Chest 2013;144:234-240. 
-41 Holland AE, Fiore JF Jr, Bell EC, Goh N, Westall G, Symons K, Dowman L, Glaspole I: Dyspnoea and comorbidity contribute to anxiety and depression in interstitial lung disease. Respirology 2014;19:1215-1221.

-42 Ryerson CJ, Arean PA, Berkeley J, CarrieriKohlman VL, Pantilat SZ, Landefeld CS, Collard HR: Depression is a common and chronic comorbidity in patients with interstitial lung disease. Respirology 2012;17:525-532.

-43 Richeldi L, du Bois RM, Raghu G, Azuma A, Brown KK, Costabel U, Cottin V, Flaherty KR, Hansell DM, Inoue Y, Kim DS, Kolb M, Nicholson AG, Noble PW, Selman M, Taniguchi H, Brun M, Le Maulf F, Girard M, Stowasser S, Schlenker-Herceg R, Disse B, Collard HR; INPULSIS Trial Investigators: Efficacy and safety of nintedanib in idiopathic pulmonary fibrosis. N Engl J Med 2014;370: 2071-2082.

-44 King TE Jr, Bradford WZ, Castro-Bernardini S, Fagan EA, Glaspole I, Glassberg MK, Gorina E, Hopkins PM, Kardatzke D, Lancaster L, Lederer DJ, Nathan SD, Pereira CA, Sahn SA, Sussman R, Swigris JJ, Noble PW; ASCEND Study Group: A phase 3 trial of pirfenidone in patients with idiopathic pulmonary fibrosis. N Engl J Med 2014;370:2083-2092.

-45 Dowman L, Hill CJ, Holland AE: Pulmonary rehabilitation for interstitial lung disease. Cochrane Database Syst Rev 2014;10:CD006322.

-46 Lacasse Y, Goldstein R, Lasserson TJ, Martin S: Pulmonary rehabilitation for chronic obstructive pulmonary disease. Cochrane Database Syst Rev 2006;4:CD003793.

-47 Holland AE, Hill CJ, Conron M, Munro P, McDonald CF: Small changes in six-minute walk distance are important in diffuse parenchymal lung disease. Respir Med 2009;103: 1430-1435.

-48 Naji NA, Connor MC, Donnelly SC, McDonnell TJ: Effectiveness of pulmonary rehabilitation in restrictive lung disease. J Cardiopulm Rehabil 2006;26:237-243.

-49 Ferreira A, Garvey C, Connors GL, Hilling L, Rigler J, Farrell S, Cayou C, Shariat C, Collard HR: Pulmonary rehabilitation in interstitial lung disease: benefits and predictors of response. Chest 2009;135:442-447.

50 Ryerson CJ, Cayou C, Topp F, Hilling L, Camp PG, Wilcox PG, Khalil N, Collard HR, Garvey C: Pulmonary rehabilitation improves long-term outcomes in interstitial lung disease: a prospective cohort study. Respir Med 2014;108:203-210.

-51 Swigris JJ, Fairclough DL, Morrison M, Make B, Kozora E, Brown KK, Wamboldt FS: Beneficial effects of pulmonary rehabilitation in idiopathic pulmonary fibrosis. Respir Care 2011;56:783-789.

52 Maltais F, Decramer M, Casaburi R, Barreiro E, Burelle Y, Debigare R, Dekhuijzen PN, Franssen F, Gayan-Ramirez G, Gea J, Gosker HR, Gosselink R, Hayot M, Hussain SN, Janssens W, Polkey MI, Roca J, Saey D, Schols AM, Spruit MA, Steiner M, Taivassalo T, Troosters T, Vogiatzis I, Wagner PD; ATS/
ERS Ad Hoc Committee on Limb Muscle Dysfunction in COPD: An official American Thoracic Society/European Respiratory Society statement: update on limb muscle dysfunction in chronic obstructive pulmonary disease. Am J Respir Crit Care Med 2014;189: e15-e62.

53 Salhi B, Troosters T, Behaegel M, Joos G, Derom E: Effects of pulmonary rehabilitation in patients with restrictive lung diseases. Chest 2010;137:273-279.

54 Gaunaurd IA, Gomez-Marin OW, Ramos CF, Sol CM, Cohen MI, Cahalin LP, Cardenas DD, Jackson RM: Physical activity and quality of life improvements of patients with idiopathic pulmonary fibrosis completing a pulmonary rehabilitation program. Respir Care 2014;59:1872-1879.

55 Holland AE, Hill CJ, Conron M, Munro P, McDonald CF: Short term improvement in exercise capacity and symptoms following exercise training in interstitial lung disease. Thorax 2008;63:549-554.

56 Holland AE, Hill CJ, Glaspole I, Goh N, McDonald CF: Predictors of benefit following pulmonary rehabilitation for interstitial lung disease. Respir Med 2012;106:429-435.

57 Kozu R, Jenkins S, Senjyu H: Effect of disability level on response to pulmonary rehabilitation in patients with idiopathic pulmonary fibrosis. Respirology 2011;16:1196-1202.

58 Nishiyama O, Kondoh Y, Kimura T, Kato K, Kataoka K, Ogawa T, Watanabe F, Arizono S, Nishimura K, Taniguchi H: Effects of pulmonary rehabilitation in patients with idiopathic pulmonary fibrosis. Respirology $2008 ; 13$ : 394-399.

59 Jackson RM, Gomez-Marin OW, Ramos CF, Sol CM, Cohen MI, Gaunaurd IA, Cahalin LP, Cardenas DD: Exercise limitation in IPF patients: a randomized trial of pulmonary rehabilitation. Lung 2014;192:367-376.

60 Baradzina HL, Ponachevnaya NV: Pulmonary rehabilitation programme in sarcoidosis (abstract). Eur Respir J 2005;26(suppl 49): $333 S$.

61 Mejia RA, Sansores RH, Perez-Padilla R, Mahler DA: Effects of exercise training on 'quality of life' in patients with interstitial lung diseases (abstract). Eur Respir J 2000;16: 330 S.

62 Menon B, Vijayan VK, Bansal V, Prajapat B: Effect of pulmonary rehabilitation on gas exchange, muscle cross section area and functional parameters in interstitial lung disease (abstract). Eur Respir J 2011;38:878S.

63 Perez Bogerd S, Wuyts W, et al: Preliminary results of pulmonary rehabilitation in interstitial lung diseases: a randomised controlled trial (abstract). Eur Respir J 2011;38:259S.

64 Vainshelboim B, Oliveira L, Yohoshua L, Weis I, Fox B, Kramer M: The effect of pulmonary rehabilitation on exercise tolerance, pulmonary function, dyspnea and quality of life in patients with idiopathic pulmonary fibrosis (abstract). Eur Respir J 2013;187: A1832.
65 Bolton CE, Bevan-Smith EF, Blakey JD, Crowe P, Elkin SL, Garrod R, Greening NJ, Heslop K, Hull JH, Man WD, Morgan MD, Proud D, Roberts CM, Sewell L, Singh SJ, Walker PP, Walmsley S; British Thoracic Society Pulmonary Rehabilitation Guideline Development G; British Thoracic Society Standards of Care C: British Thoracic Society guideline on pulmonary rehabilitation in adults. Thorax 2013;68(suppl 2):ii1-ii30.

66 Jenkins S, Cecins N: Six-minute walk test: observed adverse events and oxygen desaturation in a large cohort of patients with chronic lung disease. Intern Med J 2011;41: 416-422.

67 Park JH, Jegal Y, Shim TS, Lim CM, Lee SD, Koh Y, Kim WS, Kim WD, du Bois R, Do KH, Kim DS: Hypoxemia and arrhythmia during daily activities and six-minute walk test in fibrotic interstitial lung diseases. J Korean Med Sci 2011;26:372-378.

68 Pouwels-Fry S, Pouwels S, Fournier C, Duchemin A, Tillie-Leblond I, Le Tourneau T, Wallaert B: Effects of oxygen on exercise-induced increase of pulmonary arterial pressure in idiopathic pulmonary fibrosis. Sarcoidosis Vasc Diffuse Lung Dis 2008;25:133-139.

69 Wilsher M, Good N, Hopkins R, Young P, Milne D, Gibson A, Suppiah R, Ly J, Doughty $\mathrm{R}$, Dalbeth N: The six-minute walk test using forehead oximetry is reliable in the assessment of scleroderma lung disease. Respirology 2012;17:647-652.

70 Emtner M, Porszasz J, Burns M, Somfay A, Casaburi R: Benefits of supplemental oxygen in exercise training in nonhypoxemic chronic obstructive pulmonary disease patients. Am J Respir Crit Care Med 2003;168:10341042.

71 Hill K, Holland AE: Strategies to enhance the benefits of exercise training in the respiratory patient. Clin Chest Med 2014;35:323-336.

72 Beauchamp MK, Nonoyama M, Goldstein RS, Hill K, Dolmage TE, Mathur S, Brooks D: Interval versus continuous training in individuals with chronic obstructive pulmonary disease - a systematic review. Thorax 2010;65: 157-164.

73 Vogiatzis I, Nanas S, Roussos C: Interval training as an alternative modality to continuous exercise in patients with COPD. Eur Respir J 2002;20:12-19.

74 Vogiatzis I, Terzis G, Nanas S, Stratakos G, Simoes DC, Georgiadou O, Zakynthinos S, Roussos C: Skeletal muscle adaptations to interval training in patients with advanced COPD. Chest 2005;128:3838-3845.

75 Arnardottir RH, Boman G, Larsson K, Hedenstrom $\mathrm{H}$, Emtner $\mathrm{M}$ : Interval training compared with continuous training in patients with COPD. Respir Med 2007;101: 1196-1204.

76 Mador MJ, Krawza M, Alhajhusian A, Khan AI, Shaffer M, Kufel TJ: Interval training versus continuous training in patients with chronic obstructive pulmonary disease. J Cardiopulm Rehab Prev 2009;29:126-132. 
77 Dolmage TE, Goldstein RS: Response to onelegged cycling in patients with COPD. Chest 2006;129:325-332.

78 Dolmage TE, Goldstein RS: Effects of onelegged exercise training of patients with COPD. Chest 2008;133:370-376.

-79 Bjorgen S, Hoff J, Husby VS, Hoydal MA, Tjonna AE, Steinshamn S, Richardson RS, Helgerud J: Aerobic high intensity one and two legs interval cycling in chronic obstructive pulmonary disease: the sum of the parts is greater than the whole. Eur J Appl Physiol 2009; 106:501-507.
80 Zanotti E, Felicetti G, Maini M, Fracchia C: Peripheral muscle strength training in bedbound patients with COPD receiving mechanical ventilation: effect of electrical stimulation. Chest 2003;124:292-296.

81 Vivodtzev I, Pepin JL, Vottero G, Mayer V, Porsin B, Levy P, Wuyam B: Improvement in quadriceps strength and dyspnea in daily tasks after 1 month of electrical stimulation in severely deconditioned and malnourished COPD. Chest 2006;129:1540-1548.

82 McNamara RJ, McKeough ZJ, McKenzie DK, Alison JA: Water-based exercise in COPD with physical comorbidities: a randomised controlled trial. Eur Respir J 2013;41:12841291.
83 Schoenheit G, Becattelli I, Cohen AH: Living with idiopathic pulmonary fibrosis: an indepth qualitative survey of European patients. Chron Respir Dis 2011;8:225-231.

84 Lee AS, Mira-Avendano I, Ryu JH, Daniels $\mathrm{CE}$ : The burden of idiopathic pulmonary fibrosis: an unmet public health need. Respir Med 2014;108:955-967.

85 Burge AT, Lee A, Nicholes M, Purcell S, Miller B, Norris N, McArdle S, Sandilands S, Holland AE: Advance care planning education in pulmonary rehabilitation: a qualitative study exploring participant perspectives. Palliat Med 2013;27:508-515. 